\title{
Cyclosporine With and Without Systemic Corticosteroids in Treatment of Alopecia Areata: A Systematic Review
}

\author{
Joanna Nowaczyk - Karolina Makowska - Adriana Rakowska • \\ Mariusz Sikora $\cdot$ Lidia Rudnicka
}

Received: February 11, 2020 / Published online: April 8, 2020

(C) The Author(s) 2020

\section{ABSTRACT}

Introduction: Cyclosporine is commonly used in treatment for alopecia areata. It can be administered as a monotherapy or in combination with systemic corticosteroids, with various outcomes.

Methods: Efficacy of cyclosporine with and without systemic corticosteroids for alopecia areata was evaluated by a systematic review. Cochrane, EBSCOhost, Pubmed, Scopus and Web of Science databases were searched. Only studies published before January 2020 were included.

Results: A total of 2104 studies were initially examined, of which 14 were eligible for the systematic review. Among 340 reported cases, 213 had focal, multifocal or ophiasis form of alopecia areata, 60 were diagnosed with alopecia totalis and 67 with alopecia universalis. The mean response rate in the whole group of patients at the end of treatment was $65.00 \%$ (221/340; range 25-100\%). Hair regrowth rate

Enhanced Digital Features To view digital features for this article go to https://doi.org/10.6084/m9.figshare. 11973144

J. Nowaczyk · K. Makowska · A. Rakowska (凹) .

M. Sikora · L. Rudnicka

Department of Dermatology, Medical University of

Warsaw, Warsaw, Poland

e-mail: adriana.rakowska@gmail.com was higher in the group with cases of alopecia areata limited to scalp (124/165; mean $75.15 \%$; range $40-100 \%)$ than in the cases with alopecia totalis (30/46; mean $65.22 \%$; range $25-100 \%$ ) or alopecia universalis (24/52; mean $46.15 \%$; range 25-100\%). The combined therapy with systemic corticosteroids was superior to the monotherapy (152/219; mean $69.41 \%$; $0-80 \%$ vs. $69 / 121$; mean 57.02\%; range 6.67-100\%) and had a lower recurrence rate (39/108; mean $36.11 \%$ vs. $34 / 46$; mean $73.91 \%$, respectively). The combined treatment with methylprednisolone was significantly more effective when compared to the cyclosporine monotherapy $(124 / 183$; mean $67.76 \%$; range $0-80 \%$ vs. $69 / 121$; mean $57.02 \%$; range $6.67-100 \%)$. The mean time of treatment was 6.75 months (range 2-36).

Limitations: Limitations of our study were the retrospective character of included studies, differences in doses of prescribed drugs, and duration of the treatment and follow-up times. Conclusion: Cyclosporine in combination with oral systemic corticosteroids is more effective than in monotherapy for severe alopecia areata.

Keywords: Alopecia areata; Alopecia totalis; Alopecia universalis; Combined therapy; Corticosteroids; Cyclosporine 


\section{Key Summary Points}

Cyclosporine combined with systemic corticosteroids is more effective for alopecia areata than cyclosporine in monotherapy.

The combined therapy allows one to reduce dose of cyclosporine.

Relapses are less frequently correlated with the combined therapy.

Large extend of skin involvement could be a risk factor of a negative treatment response.

\section{INTRODUCTION}

Alopecia areata (AA) is an autoimmune disease manifesting itself as a single or multiple patches of non-scarring hair loss. The condition most commonly is observed only on the scalp [1] but sporadically appears on other body parts as well. It affects both the paediatric and adult populations. This disease is characterized by a recurrent hair loss without any clinical inflammatory signs [2] or other systemic symptoms.

The pathogenesis of AA is still unclear. Many highlight that factors such as stress [3], impaired hormonal system [4], infectious agents [5] and genetic predispositions [6] might have some connection with the disease. The interplay between one's genes and factors present in their environment are likely part of this autoimmune disease $[7,8]$. The frequent coexistence of AA with other autoimmune disorders such as hypothyroidism, psoriasis [9] and vitiligo [8] supports this hypothesis.

The disease has a noticeable impact on the patient's appearance and thus its influence on the quality of life (QoL) is significant [10-12]. In the majority of cases, it is a self-limiting condition (with spontaneous remission within 12 months in about half of the cases [11]). However, when the hair regrowth is not observed, it is important to implement effective treatment. As a result of the lack of clear standards, various medications are used with no coherent guidelines on the dosage and drug administration routes [7]. Many treatment options are currently known, including topical, intralesional or systemic corticosteroids [7], cyclosporine (CsA), methotrexate (MTX) [13], JAK inhibitors [14, 15], diphencyprone (DPCP) [16] and phototherapy [17]. New biological treatments are becoming available $[14,15]$; however, many of them are out of patients' reach because of the associated high cost.

CsA is a calcineurin inhibitor used to prevent allogeneic organ rejection [10] and to treat many autoimmune disorders [18]. CsA is used as an adjunct to corticosteroid therapy for AA as well as in a monotherapy $[7,19]$. Protocols with various dosage regimens, treatment durations and corticosteroids used have been described to date [20]. The lack of unambiguous guidelines in the selection of a treatment algorithm for AA is an ongoing issue for evidence-based practitioners.

The aim of this study is to determine the difference in treatment outcomes of patients with AA treated with CsA in monotherapy compared to those receiving CsA with systemic corticosteroids, the risk of relapse in the each treatment regimen, the frequency and the severity of side effects for the compared treatments and the treatment efficacy depending on the type of disease.

\section{METHODS}

\section{Protocol and Registration}

This review was reported in compliance with the PRISMA guidelines [21]. This article is based on previously conducted studies and does not contain any studies with human participants or animals performed by any of the authors.

\section{Eligibility Criteria}

Selection criteria were the use of cyclosporine in monotherapy or in a combination with 
systemic corticosteroids in patients with AA. Full-text papers of case series and retrospective studies meeting eligibility criteria were included. Conference abstracts following the STROBE statement for conference abstracts [22] were included. Case reports were excluded. Papers in which additional therapies such as PUVA and minoxidil were used simultaneously with the administration of cyclosporine were excluded. Articles which did not report response rates were also eliminated from the analysis.

\section{Information Sources and Search Strategy}

Cochrane, EBSCOhost, PubMed, Embase, Scopus and Web of Science databases were searched for eligible studies. Dates of coverage were restricted to articles published before January 2020. The last search was performed on 26 December 2019.

A combination of keywords 'alopecia areata' and 'cyclosporine' was used as search terms in 'all fields' or 'all text', or 'total text' search category. No time or language criteria were applied.

\section{Extraction of the Data}

The articles were screened by two independent researchers. Discrepancies were discussed and resolved by the means of a consensus. The data was obtained from the texts, tables, charts or figures in the papers. Number of patients, age, gender, subtype of disease, treatment regimen dosage, follow-up period and relapses were extracted from the eligible papers.

\section{Data Assessment and Classification}

Patients classified in the study were described in papers as "severe", "refractory" or "at least 50\% scalp involvement" AA. Criteria of good response were not consistent-either not provided, evaluated by self-assessment [23] or assessment by clinician with any regrowth [24], at least $50 \%[25,26], 70 \%[27,28]$ or $75 \%$ [29] regrowth.

Patients were divided into three groups based on their symptoms. Those with focal, multifocal (patchy) or ophiasis-type AA with incomplete (less than 100\%) scalp hair loss were simply referred to as "fmoAA". Alopecia totalis (AT) was assigned for cases with complete scalp hair loss (with the exception of a study by Shapiro et al. [29], who used a criterion of 95\% hair loss). Patients presenting both complete $(100 \%)$ hair loss on the scalp and on other body parts (to various extents) were described using the term of alopecia universalis (AU).

\section{Statistical Analysis}

Results were presented using means with ranges and/or standard deviations. As a result of the small number of head-to-head clinical trials comparing two main modalities of the treatment of AA, a naïve direct comparison approach was used. A meta-analysis of proportions with random effects model was used to investigate the outcomes of treatment and recurrence rates. Funnel plots were created to assess the heterogeneity of the results and $I^{2}$ greater than 50\% was considered as substantial. Egger regression test was used to investigate the presence of publication bias. Analyses were created with statistical software environment R 3.6.2 [30].

\section{Study Quality and Risk of Bias Across Studies}

A limited amount of data is available regarding the CsA monotherapy and the combined treatment. A vast number of papers present case reports, which were excluded in this study because of their low level of evidence.

\section{RESULTS}

\section{Study Selection}

A total of 2104 results were retrieved from the database search. Fourteen papers fulfilled the selection criteria and were included in this study. The process of a study selection is presented in Fig. 1.

Among a total of 340 patients, 213 had fmoAA, 60 had alopecia totalis (AT) and 67 had 


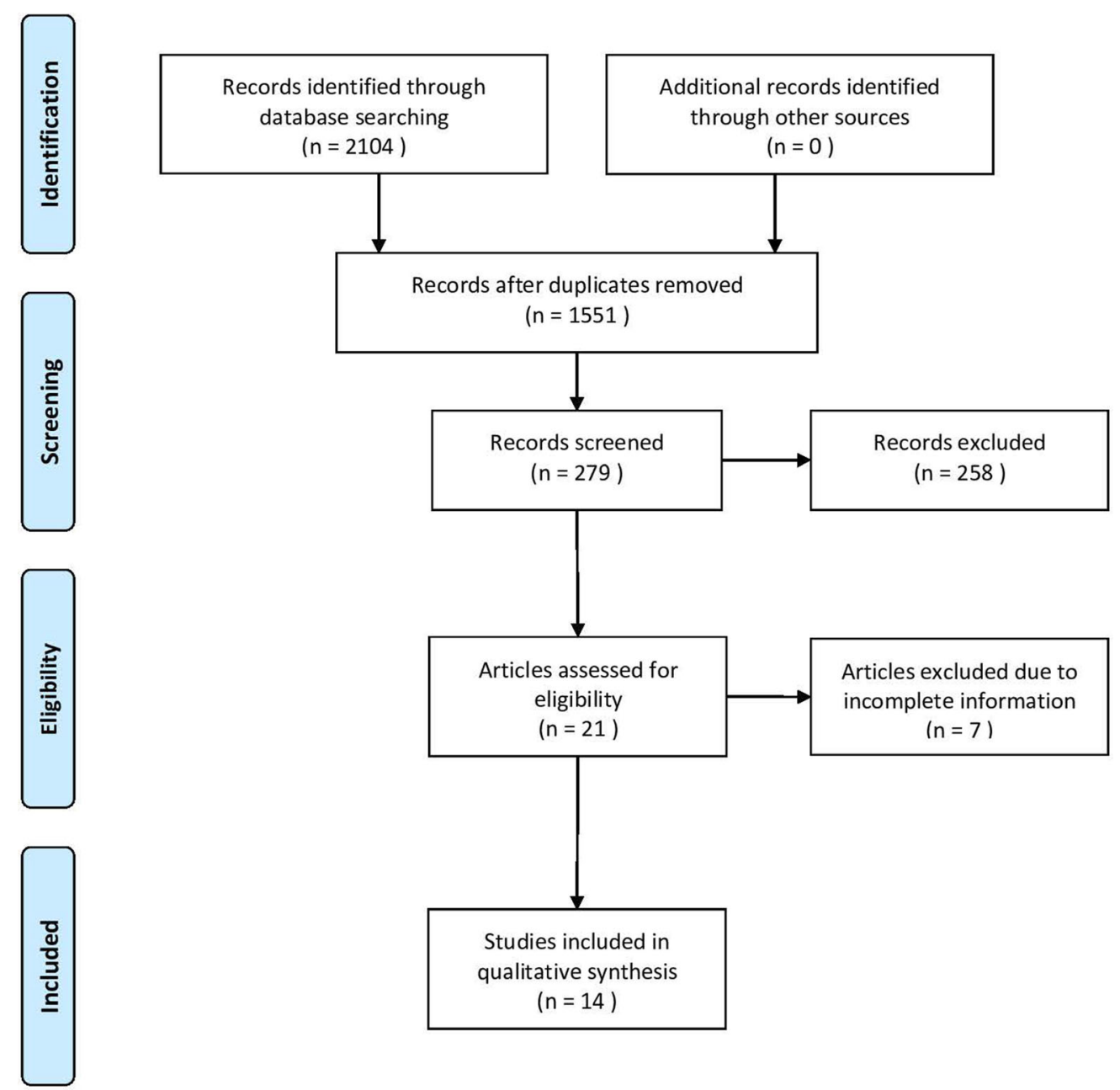

Fig. 1 Flow chart of data extraction following PRISMA guidelines

alopecia universalis (AU). The male to female gender ratio was 155:138 (Lee et al. [31] and Gadzhigoroeva [32] did not provide gender distributions). The mean age of patients was 26.7 years (range 1-80, SD 9.15, 95\% CI 21-32.4; excluding missing data in Gupta et al. [33] and Lee et al. [31]). Separating the paediatric population from the adults was not feasible because of the unavailability of data.

In the papers selected, the primary severity of the disease was assessed according to the SALT scale [34], the percentage of scalp involvement, and the size of lesions (in centimetres). In the majority of articles, a "good response" was defined as either a regrowth of more than $50 \%$ or as a cosmetically acceptable effect.
Cyclosporine administration was exclusively oral while an intravenous and oral administration was used in the case of systemic corticosteroids (Tables 1, 2).

\section{Assessment of Treatment Efficacy}

The mean response rate of the whole group at the end of treatment was $65.00 \%(221 / 340$; range $25-100 \%)$. The overall hair regrowth rates regardless of type of therapy were higher in the group with fmoAA (124/165; mean $75.15 \%$; range $40-100 \%)$ than in AT (30/46; mean $65.22 \%$; range $25-100 \%)$ or $\mathrm{AU}$ (24/52; mean 46.15\%; range $25-100 \%)$. Articles with missing response rates in alopecia areata were not 


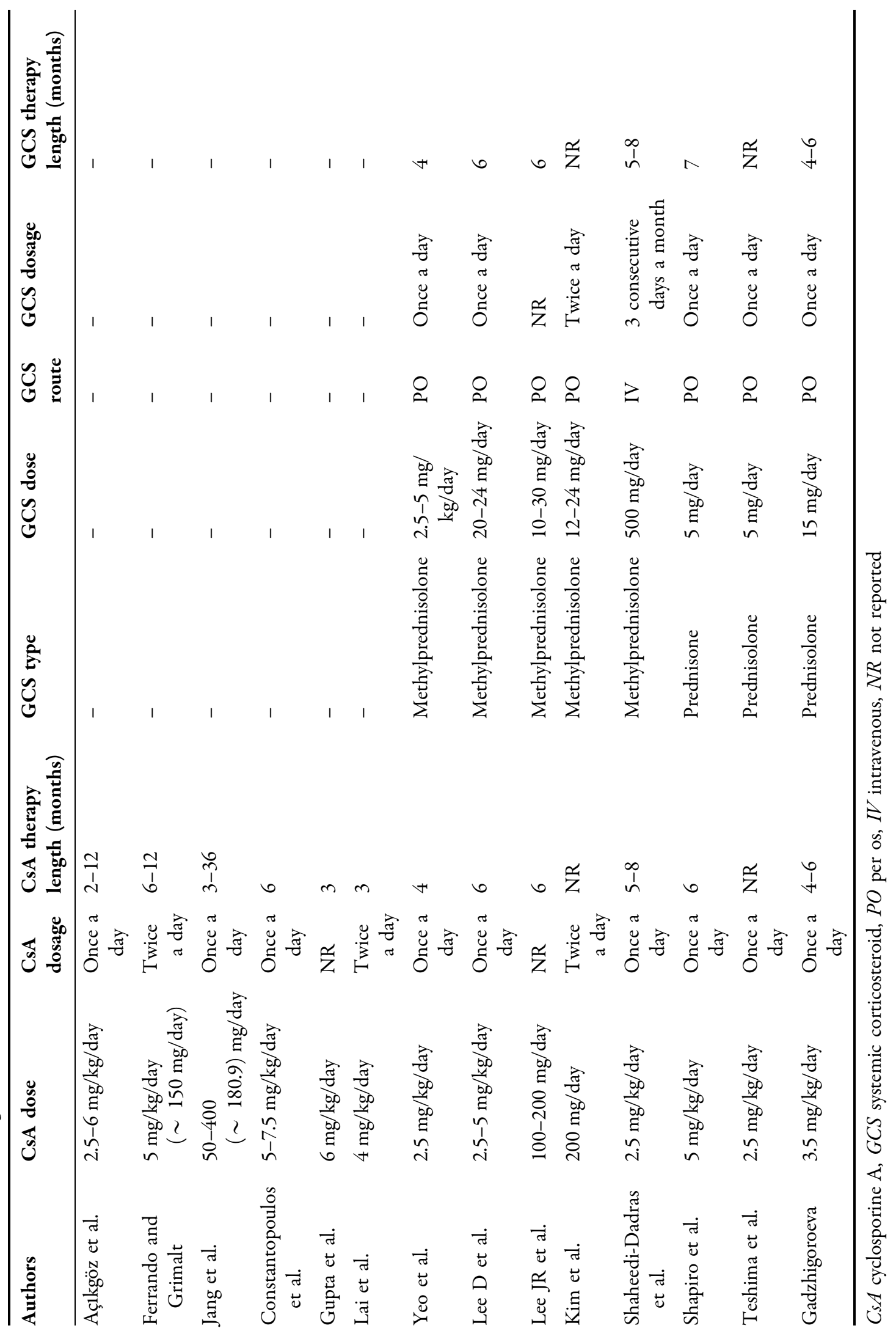


Table 2 Effective treatment and relapses in selected studies

\begin{tabular}{|c|c|c|c|c|c|c|c|}
\hline Authors & $\begin{array}{l}\text { Therapy } \\
\text { regime }\end{array}$ & Type & $\begin{array}{l}\text { Number of } \\
\text { patients }\end{array}$ & $\begin{array}{l}\text { Number of } \\
\text { effective } \\
\text { treatments }\end{array}$ & $\begin{array}{l}\% \text { of effective } \\
\text { treatment }\end{array}$ & $\begin{array}{l}\text { Number of } \\
\text { relapses }\end{array}$ & $\begin{array}{l}\% \text { of } \\
\text { relapses }\end{array}$ \\
\hline \multirow[t]{3}{*}{ Aç1kgöz et al. } & \multirow{3}{*}{$\begin{array}{l}\text { CsA } \\
\text { monotherapy }\end{array}$} & fmoAA & 12 & 5 & 41.67 & \multirow[t]{3}{*}{ NR } & \multirow[t]{3}{*}{ NR } \\
\hline & & AT & 4 & 2 & 50.00 & & \\
\hline & & $\mathrm{AU}$ & 9 & 3 & 33.33 & & \\
\hline \multirow{3}{*}{$\begin{array}{l}\text { Ferrando and } \\
\text { Grimalt }\end{array}$} & \multirow{3}{*}{$\begin{array}{l}\text { CsA } \\
\text { monotherapy }\end{array}$} & fmoAA & 5 & 2 & 40.00 & \multirow[t]{3}{*}{1} & \multirow[t]{3}{*}{6.67} \\
\hline & & AT & 2 & 2 & 100 & & \\
\hline & & $\mathrm{AU}$ & 8 & 3 & 37.50 & & \\
\hline \multirow[t]{3}{*}{ Jang et al. } & \multirow{3}{*}{$\begin{array}{l}\text { CsA } \\
\text { monotherapy }\end{array}$} & fmoAA & 40 & \multirow[t]{3}{*}{28} & \multirow[t]{3}{*}{54.90} & \multirow[t]{3}{*}{22} & \multirow[t]{3}{*}{43.14} \\
\hline & & AT & 6 & & & & \\
\hline & & $\mathrm{AU}$ & 5 & & & & \\
\hline $\begin{array}{l}\text { Constantopoulos } \\
\text { et al. }\end{array}$ & $\begin{array}{l}\text { CsA } \\
\text { monotherapy }\end{array}$ & fmoAA & 6 & 5 & 83.33 & 5 & 83.33 \\
\hline Gupta et al. & $\begin{array}{l}\text { CsA } \\
\text { monotherapy }\end{array}$ & fmoAA & 6 & 6 & 100 & 6 & 100 \\
\hline \multirow[t]{3}{*}{ Lai et al. } & \multirow{3}{*}{$\begin{array}{l}\text { CsA } \\
\text { monotherapy }\end{array}$} & fmoAA & 8 & 13 & 72.22 & NR & NR \\
\hline & & AT & 4 & & & & \\
\hline & & $\mathrm{AU}$ & 6 & & & & \\
\hline \multirow[t]{3}{*}{ Yeo et al. } & \multirow{3}{*}{$\begin{array}{l}\text { CsA + GCS } \\
\text { PO }\end{array}$} & fmoAA & 44 & 24 & 54.55 & \multirow[t]{3}{*}{8} & \multirow[t]{3}{*}{13.33} \\
\hline & & $\mathrm{AT}$ & 10 & 4 & 40.00 & & \\
\hline & & $\mathrm{AU}$ & 6 & 3 & 50.00 & & \\
\hline \multirow[t]{3}{*}{ Lee $\mathrm{D}$ et al. } & \multirow{3}{*}{$\begin{array}{l}\text { CsA + GCS } \\
\text { PO }\end{array}$} & fmoAA & 19 & 15 & 78.95 & \multirow[t]{3}{*}{ NR } & \multirow[t]{3}{*}{ NR } \\
\hline & & AT & 7 & 4 & 57.14 & & \\
\hline & & $\mathrm{AU}$ & 8 & 5 & 62.50 & & \\
\hline \multirow[t]{2}{*}{ Lee JR et al. } & \multirow{2}{*}{$\begin{array}{l}\text { CsA + GCS } \\
\text { PO }\end{array}$} & fmoAA & 19 & 19 & 100 & \multirow[t]{2}{*}{20} & \multirow[t]{2}{*}{80.00} \\
\hline & & AT & 6 & 6 & 100 & & \\
\hline \multirow[t]{3}{*}{ Kim et al. } & \multirow{3}{*}{$\begin{array}{l}\text { CsA + GCS } \\
\text { PO }\end{array}$} & fmoAA & 32 & 28 & 87.50 & 9 & 19.57 \\
\hline & & AT & 11 & 9 & 81.82 & & \\
\hline & & $\mathrm{AU}$ & 3 & 1 & 33.33 & & \\
\hline Shaheedi-Dadras & CsA + GCS & $\mathrm{AT}$ & 6 & 3 & 50.00 & 0 & 0 \\
\hline et al. & IV & $\mathrm{AU}$ & 12 & 3 & 25.00 & & \\
\hline Shapiro et al. & CsA + GCS & AT & 4 & 2 & 25.00 & 2 & 25.00 \\
\hline & $\mathrm{PO}$ & $\mathrm{AU}$ & 4 & & & & \\
\hline
\end{tabular}


Table 2 continued

\begin{tabular}{llllllll}
\hline Authors & $\begin{array}{l}\text { Therapy } \\
\text { regime }\end{array}$ & Type & $\begin{array}{l}\text { Number of } \\
\text { patients }\end{array}$ & $\begin{array}{l}\text { Number of } \\
\text { effective } \\
\text { treatments }\end{array}$ & $\begin{array}{l}\text { \% of effective } \\
\text { treatment }\end{array}$ & $\begin{array}{l}\text { Number of } \\
\text { relapses of }\end{array}$ & $\begin{array}{l}\text { \% } \\
\text { relapses }\end{array}$ \\
\hline Teshima et al. & $\begin{array}{c}\mathrm{CsA}+\mathrm{GCS} \\
\mathrm{PO}\end{array}$ & $\mathrm{AU}$ & 6 & 6 & 100 & 0 & 0 \\
Gadzhigoroeva & $\begin{array}{c}\mathrm{CsA}+\mathrm{GCS} \\
\mathrm{PO}\end{array}$ & fmoAA & 22 & 20 & 90.91 & $\mathrm{NR}$ & $\mathrm{NR}$ \\
& & & & & & & \\
\hline
\end{tabular}

$C s A$ cyclosporine A, $G C S$ systemic corticosteroid, $P O$ per os, $I V$ intravenous, fmo $A A$ focal, multifocal or ophiasis-type alopecia areata, $A T$ alopecia totalis, $A U$ alopecia universalis, $N R$ not reported

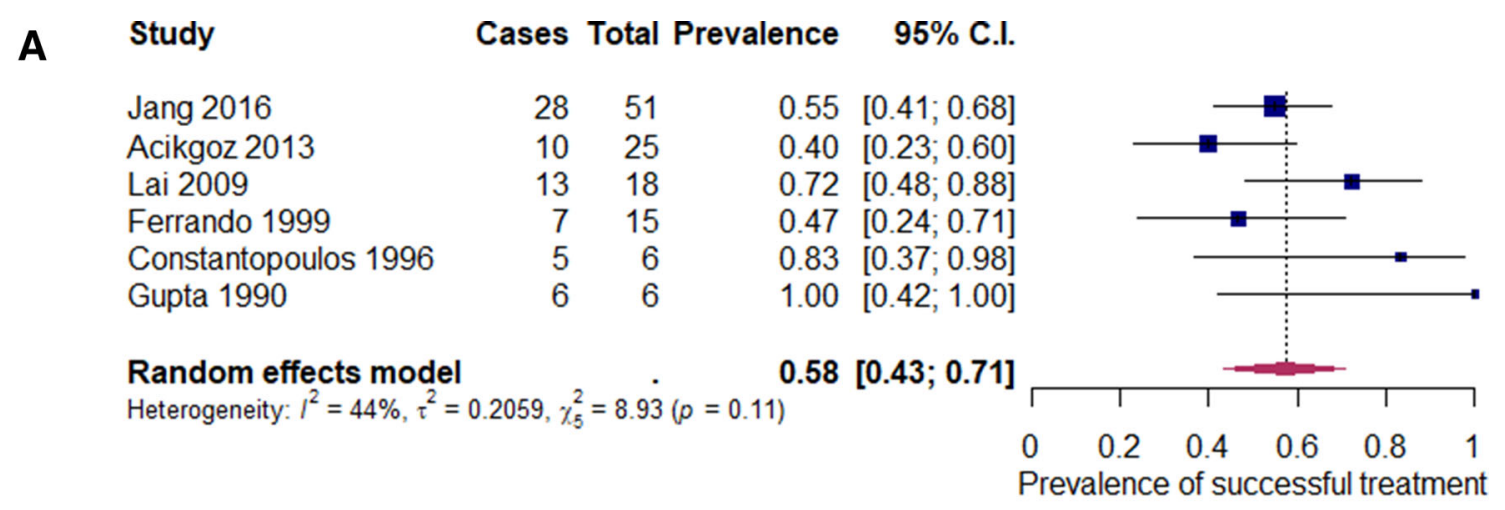

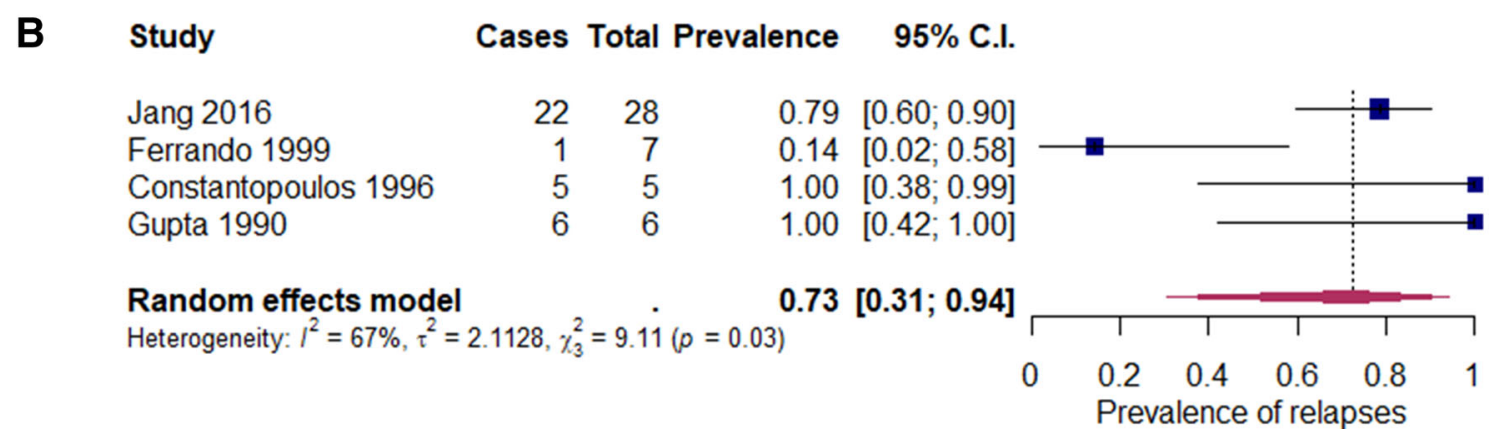

Fig. 2 Analysis of proportions for monotherapy: a successful treatment $(p=0.11)$, b relapses $(p=0.03)$

included in the statistical analysis (applies to Jang et al. [23], Shapiro et al. [29] and Lai et al. [35]).

\section{Assessment of Corticosteroid-Combined Therapy vs. Monotherapy}

Efficacy of the combined treatment was higher in comparison to CsA in monotherapy (152/ 219; mean 69.41\%; range $0-80 \%$ vs. $69 / 121$; mean 57.02\%; range 6.67-100\%). Articles with missing information about response rates in each subtype of alopecia areata were not included in the statistical analysis (applies to Jang et al. [23], Shapiro et al. [29] and Lai et al. [35]). Successful treatment in monotherapy was characterised by low heterogeneity in comparison to combined therapy (Figs. 2a, 3a).

Methylprednisolone was the most commonly used corticosteroid, administered mainly 
A Study

Yeo 2005
Kim 2007
Lee D 2008
Lee JR 2009
Gadzhigoroeva 2013
Shaheedi-Dadras 2008
Shapiro 1997
Teshima 1992

Cases Total Prevalence $\quad 95 \%$ C.I.

$\begin{array}{rr}31 & 60 \\ 38 & 46 \\ 24 & 34 \\ 25 & 25 \\ 20 & 22 \\ 6 & 18 \\ 2 & 8 \\ 6 & 6\end{array}$

$\begin{array}{ll}0.52 & {[0.39 ; 0.64]} \\ 0.83 & {[0.69 ; 0.91]} \\ 0.71 & {[0.53 ; 0.83]} \\ 1.00 & {[0.76 ; 1.00]} \\ 0.91 & {[0.70 ; 0.98]} \\ 0.33 & {[0.16 ; 0.57]} \\ 0.25 & {[0.06 ; 0.62]} \\ 1.00 & {[0.42 ; 1.00]}\end{array}$

$0.70[0.50 ; 0.84]$

Random effects model Heterogeneity: $I^{2}=80 \%, \tau^{2}=0.9851, \chi_{7}^{2}=34.30(p<0.01)$



\section{B Study}

Yeo 2005

Kim 2007

Lee JR 2009

Shaheedi-Dadras 2008

Shapiro 1997

Teshima 1992

\section{Cases Total Prevalence $\quad 95 \%$ C.I.}

Random effects model Heterogeneity: $I^{2}=80 \%, \tau^{2}=1.5644, \gamma_{5}^{2}=24.86(p<0.01)$

$\begin{array}{rr}8 & 31 \\ 9 & 38 \\ 20 & 25 \\ 0 & 6 \\ 2 & 2 \\ 0 & 6\end{array}$



Fig. 3 Analysis of proportions for combined therapy: a successful treatment $(p<0.01)$, b relapses $(p<0.01)$

orally (Shaheedi-Dadras et al. [27] only used the intravenous route), with a mean response rate at the end of therapy of $67.76 \%(124 / 183$; range 0-80\%). The combined treatment with methylprednisolone was significantly more effective in comparison to CsA monotherapy (124/183; mean 67.76\%; range $0-80 \%$ vs. 69/121; mean 57.02\%; range 6.67-100\%).

\section{Mean Time of Treatment/Time to Effect}

The duration of the treatment ranged from 2 to 36 months. The mean time of the treatment (data not extractable in two studies: Teshima et al. [36], Kim et al. [24]) was 6.75 months (SD 4.36, 95\% CI 4.28-9.22).

Time to effect varied from 0.69 to 5.8 months. From the available data from seven studies (which included 180 patients) time to effect was 2.45 months (SD 1.75, 95\% CI 1.15-3.75).

\section{Assessment of Recurrence}

The total recurrence rate was $47.40 \%(73 / 154$, range $0-100 \%)$. CsA therapy with systemic corticosteroids was characterized by significantly lower recurrence rates in comparison to the CsA monotherapy algorithm (39/108; mean 36.11\%; range $0-80 \%$ and $34 / 46$; mean $73.91 \%$, range $6.67-100 \%$, respectively). Heterogeneity of both groups was high (Figs. 2b, 3b). Methylprednisolone combined therapy also showed smaller relapse rate compared to monotherapy $(37 / 100$; mean $37.0 \%$; range $0-80 \%$ vs. $34 / 46$; mean 73.91\%; range 6.67-100\%). 


\section{Assessment of Side Effects}

Data regarding the side effects were incomplete and the analysis was conducted on the basis of the available information (Lee et al. [31] and Gadzhigoroeva [32] mentioned the exact side effects, yet did not provide the number of patients affected). If the occurrence of exact adverse effect was mentioned in the article but the number of patients was not provided, we decided to use $a$ ' $\geq$ ' sign instead of ' $=$ ' next to the countable sum to indicate the presence of this adverse effect. Side effects were observed in $36.76 \%$ patients $(125 / 340)$. Gastrointestinal problems $(n \geq 28)$, hypertrichosis $(n \geq 20)$ and hypertension $(n \geq 9)$ were the most common side effects of therapy, regardless of the therapy regimen. Other symptoms included dyslipidaemia $(n \geq 8)$, headaches $(n \geq 7)$, oedema ( $n$ $\geq 6)$, weight gain $(n=6)$, acneiform eruption $(n=5)$, hirsutism $(n=5), \quad$ musculoskeletal complaints $(n=3)$, respiratory disorders $(n=3)$, menstrual abnormalities $(n=2)$, weakness $(n=2)$, abnormal liver function tests $(n \geq 1)$, haematuria $(n=1)$, hyperbilirubinemia $(n=1)$, gingival hyperplasia $(n=1)$, paraesthesia $(n=1)$, urinary tract infection $(n=1)$, pruritus $(n=1)$ and ophthalmologic disorders $(n=1)$. Seven patients $(7 / 340,2.06 \%)$ were withdrawn from the treatment because of unacceptable adverse effects, mostly presenting themselves with hypertrichosis $(n \geq 3)$ and hypertension ( $n$ $\geq 2$ ), as well as menstrual abnormalities, generalized oedema, abnormal results of the liver function tests or abnormal lipid levels.

\section{Assessment of Dosage}

A mean dose of $5.1 \mathrm{mg} / \mathrm{kg} /$ day (SD 1.01, 95\% CI $4.21-5.98 \mathrm{mg} / \mathrm{kg} /$ day) in monotherapy was reduced to $3.29 \mathrm{mg} / \mathrm{kg} /$ day (SD 1.01, 95\% CI $2.48-4.1 \mathrm{mg} / \mathrm{kg} /$ day) when systemic corticosteroids were added (the value calculated disregarding the works of Jang et al. [23], Lee et al. [31] and Kim et al. [24] because of a different dosage unit).
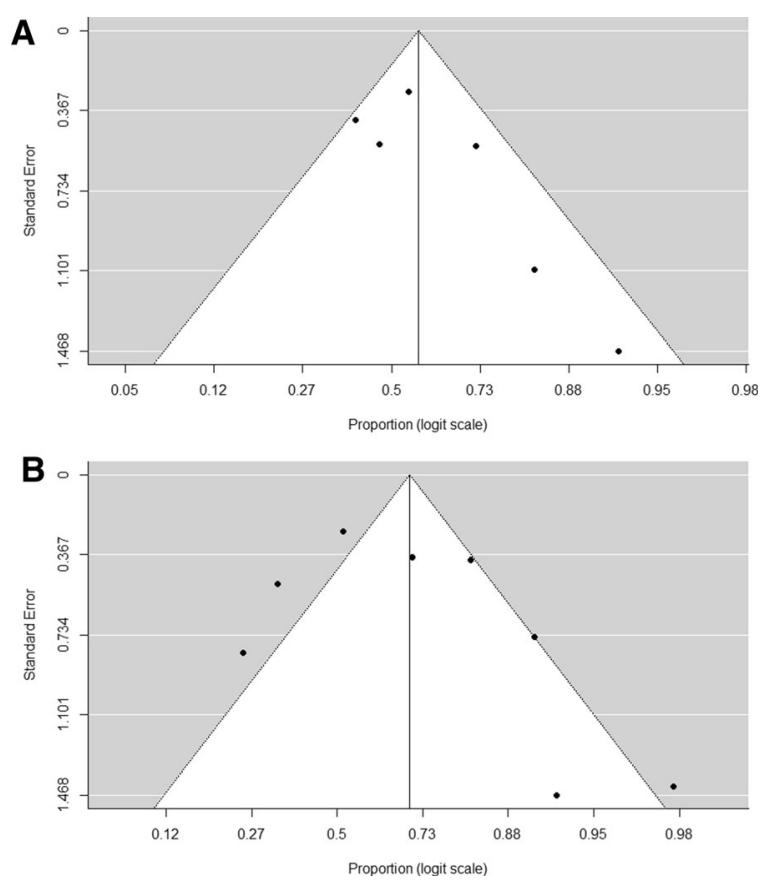

Fig. 4 Assessment of risk of bias: a for successful treatment in monotherapy (Egger test, $z=1.718$, $p=0.086)$, $\mathbf{b}$ for successful treatment in combined therapy (Egger test, $z=1.984, p=0.047$ )

\section{Publication Bias}

Regression test for funnel plot asymmetry revealed the presence of publication bias on an outcome defined as successful treatment $(p=0.047)$ (Fig. 4a). Bias did not exist for combined therapies ( $p=0.086$ ) (Fig. $4 b$ ).

\section{DISCUSSION}

The treatment of alopecia areata is demanding and there are no clear guidelines for the therapy. Depending on the severity and the extent of the skin lesions, treatments have varying efficacies-hair regrowth rates depend on the severity of the disease. Our analysis shows that treatment outcomes of AU seem to be poorer for both the mono- and the combined therapy. The cause of recurrence might be withdrawal or discontinuation either of the cyclosporine monotherapy or the combination therapy with systemic corticosteroids. Our analysis supports the hypothesis that if a less extensive area of the 
body is occupied by the disease, the effects achieved in a combined therapy are better than those obtained when using monotherapy. Combination treatment helped to achieve better outcomes both in hair regrowth and recurrence of disease in comparison to monotherapy. This was possibly due to complex interactions between corticosteroid metabolic pathways [37].

Our analysis showed that the addition of systemic corticosteroids to cyclosporine therapy may be beneficial in severe alopecia areata as it leads to considerably fewer relapses. This point should be further investigated in prospective research. Maintenance of remission phase is the aim for clinicians and is challenging because of the recurring nature of the disease [38, 39]. Gupta et al. [33] reported 100\% (6/6) recurrence rate of the disease after discontinuation of the CsA monotherapy. On the contrary, Teshima et al. [36] showed a complete persistence of the regrowth in a group of the same size (6/6) using a combination therapy. Shaheedi-Dadras et al. [27] presented a maintained hair growth after the discontinuation of the combined therapy $(3 / 3)$.

Compared to monotherapy, cyclosporine combined therapy enables one to achieve the same or better efficacy while using lower cyclosporine doses. It is an important aspect of the treatment, as lower doses of cyclosporine contribute to a decreased risk of developing severe side effects, such as nephrotoxicity or immune suppression [7]. Lee et al. concluded that the combined therapy has a steroid-sparing effect due to decreased toxicity when compared to the CsA or the corticosteroid monotherapy alone [25].

According to Shapiro et al., hypertrichosis is another significant side effect occurring in approximately $80 \%$ of patients treated with CsA [29]. It is dose-dependent [26] and likely results from the prolongation of anagen phase [24], as well as the elimination of lymphocytes from hair follicles [25]. Hypertrichosis is an undesirable consequence of the therapy due to occurrence in normally hairless regions and is considered to be one of the most frequent adverse effects, next to gastrointestinal disturbances and hypertension. The adverse effects appear despite the combination of CsA with steroids. Nonetheless, dramatic adverse reactions are not reported in patients in the analysed papers. Lee et al. mentioned that the side effects observed in 12 patients were transient and manageable [25]. Ferrando and Grimalt only reported minimal hypertrichosis among patients [28]. According to Lai et al. the incidence of side effects in placebo and cyclosporine groups was similar and there were no statistically significant differences [35]. In the papers analysed, four patients discontinued therapy as a result of side effects, including hypertension, hypertrichosis and menstrual abnormalities. Unfortunately, it is impossible to assess if the dose of cyclosporine had any impact.

The optimal treatment time is not strictly defined [18]. Reported duration of the therapy ranged from 2 to 36 months. The first effects of successful treatment were observed after 0.695.8 months from the start of the therapy.

\section{Study Limitations}

Discrepancies in the cases of the separate fmoAA, AT and AU groups of mono- and combined therapy are present. We hypothesize that this is due to the small number of patients in the subgroups.

Moreover, case series included in the analysis consisted of at least six patients, which is a sparse group comparing to observational, retrospective or prospective studies and clinical trials.

\section{CONCLUSION}

Treatment of AA seems to be more effective with CsA in combination with systemic corticosteroids (the most frequently selected therapy was methylprednisolone), which also allows one to reduce the dose of CsA and obtain less severe side effects. The less extensive area of the body is occupied by the disease, the better results might be expected. Moreover, relapses occur less frequently in patients receiving the combined therapy. 


\section{ACKNOWLEDGEMENTS}

The authors would like to thank Michał Zawistowski and Tomasz Rakowski for significant help in statistical analysis.

Funding. No funding or sponsorship was received for this study or publication of this article.

Authorship. All named authors meet the International Committee of Medical Journal Editors (ICMJE) criteria for authorship for this article, take responsibility for the integrity of the work as a whole, and have given their approval for this version to be published.

Authorship Contributions. Makowska, Nowaczyk and Rakowska designed the study. Makowska and Nowaczyk searched the literature and extracted the data. All authors were involved in the statistical analysis and interpretation of the results. Makowska and Nowaczyk wrote the manuscript which was then revised and approved by the rest of authors.

Disclosures. Joanna Nowaczyk, Karolina Makowska, Adriana Rakowska, Mariusz Sikora and Lidia Rudnicka have nothing to disclose.

Compliance with Ethics Guidelines. This article is based on previously conducted studies and does not contain any studies with human participants or animals performed by any of the authors.

Data Availability. The datasets generated during and/or analyzed during the current study are available from the corresponding author on reasonable request.

Open Access. This article is licensed under a Creative Commons Attribution-NonCommercial 4.0 International License, which permits any non-commercial use, sharing, adaptation, distribution and reproduction in any medium or format, as long as you give appropriate credit to the original author(s) and the source, provide a link to the Creative Commons licence, and indicate if changes were made. The images or other third party material in this article are included in the article's Creative Commons licence, unless indicated otherwise in a credit line to the material. If material is not included in the article's Creative Commons licence and your intended use is not permitted by statutory regulation or exceeds the permitted use, you will need to obtain permission directly from the copyright holder. To view a copy of this licence, visit http:// creativecommons.org/licenses/by-nc/4.0/.

\section{REFERENCES}

1. Wasserman D, Guzman-Sanchez DA, Scott K, McMichael A. Alopecia areata. Int J Dermatol. 2007;46(2):121-31.

2. Seetharam KA. Alopecia areata: an update. Indian J Dermatol Venereol Leprol. 2013;79(5):563-75.

3. Elenkov IJ, Chrousos GP. Stress hormones, proinflammatory and antiinflammatory cytokines, and autoimmunity. Ann N Y Acad Sci. 2002;966: 290-303.

4. McElwee KJ, Silva K, Beamer WG, King LE Jr, Sundberg JP. Melanocyte and gonad activity as potential severity modifying factors in $\mathrm{C} 3 \mathrm{H} / \mathrm{HeJ}$ mouse alopecia areata. Exp Dermatol. 2001;10(6): 420-9.

5. Rodriguez TA, Duvic M, National Alopecia Areata Registry. Onset of alopecia areata after Epstein-Barr virus infectious mononucleosis. J Am Acad Dermatol. 2008;59(1):137-9.

6. Petukhova L, Cabral RM, MacKay-Wiggan J, Clynes $\mathrm{R}$, Christiano AM. The genetics of alopecia areata: what's new and how will it help our patients? Dermatol Ther. 2011;24(3):326-36.

7. Alkhalifah A, Alsantali A, Wang E, McElwee KJ, Shapiro J. Alopecia areata update. Part II. Treatment. J Am Acad Dermatol. 2010;62(2):191-202.

8. Wang E, McElwee KJ. Etiopathogenesis of alopecia areata: why do our patients get it? Dermatol Ther. 2011;24(3):337-47.

9. Barahmani N, Schabath MB, Duvic M, National Alopecia Areata Registry. History of atopy or autoimmunity increases risk of alopecia areata. J Am Acad Dermatol. 2009;61(4):581-91. 
10. Amin SS, Sachdeva S. Alopecia areata: a review. J Saudi Soc Dermatol Dermatol Surg. 2013;17(2): $37-45$.

11. Harries MJ, Sun J, Paus R, King LE Jr. Management of alopecia areata. BMJ. 2010;341:c3671.

12. Rencz F, Baji P, Gulacsi L, et al. Discrepancies between the Dermatology Life Quality Index and utility scores. Qual Life Res. 2016;25(7):1687-96.

13. Phan K, Ramachandran V, Sebaratnam DF. Methotrexate for alopecia areata: a systematic review and meta-analysis. J Am Acad Dermatol. 2019;80(1):120-7.e2.

14. Phan K, Sebaratnam DF. JAK inhibitors for alopecia areata: a systematic review and meta-analysis. J Eur Acad Dermatol Venereol. 2019;33(5):850-6.

15. Gilhar A, Keren A, Paus R. JAK inhibitors and alopecia areata. Lancet. 2019;393(10169):318-9.

16. Singh G, Lavanya M. Topical immunotherapy in alopecia areata. Int J Trichol. 2010;2(1):36-9.

17. Ohtsuki A, Hasegawa T, Komiyama E, Takagi A, Kawasaki J, Ikeda S. 308-nm excimer lamp for the treatment of alopecia areata: clinical trial on 16 cases. Indian J Dermatol. 2013;58(4):326.

18. Amor KT, Ryan C, Menter A. The use of cyclosporine in dermatology: part I. J Am Acad Dermatol. 2010;63(6):925-46.

19. Shapiro J. Current treatment of alopecia areata. J Investig Dermatol Symp Proc. 2013;16(1):S42-4.

20. Berth-Jones J, Exton LS, Ladoyanni E, et al. British Association of Dermatologists guidelines for the safe and effective prescribing of oral ciclosporin in dermatology 2018. Br J Dermatol. 2019;180(6): 1312-38.

21. Moher D, Liberati A, Tetzlaff J, Altman DG, PRISMA Group. Preferred reporting items for systematic reviews and meta-analyses: the PRISMA statement. J Clin Epidemiol. 2009;62(10):1006-12.

22. von Elm E, Altman DG, Egger $M$, et al. The Strengthening the Reporting of Observational Studies in Epidemiology (STROBE) statement: guidelines for reporting observational studies. J Clin Epidemiol. 2008;61(4):344-9.

23. Jang YH, Kim SL, Lee KC, et al. A comparative study of oral cyclosporine and betamethasone minipulse therapy in the treatment of alopecia areata. Ann Dermatol. 2016;28(5):569-74.

24. Kim BJ, Uk Min S, Park KY, et al. Combination therapy of cyclosporine and methylprednisolone on severe alopecia areata. J Dermatol Treat. 2008;19(4):216-20.

25. Lee D, Oh DJ, Kim JW, et al. Treatment of severe alopecia areata: combination therapy using systemic cyclosporine A with low dose corticosteroids. Ann Dermatol. 2008;20(4):172-8.

26. Yeo IK, Ko EJ, No YA, et al. Comparison of highdose corticosteroid pulse therapy and combination therapy using oral cyclosporine with low-dose corticosteroid in severe alopecia areata. Ann Dermatol. 2015;27(6):676-81.

27. Shaheedi-Dadras M, Karami A, Mollaei M, Moravej T, Malekzad F. The effect of methylprednisolone pulse-therapy plus oral cyclosporine in the treatment of alopecia totalis and universalis. Arch Iran Med. 2008;11(1):90-3.

28. Ferrando J, Grimalt R. Partial response of severe alopecia areata to cyclosporine A. Dermatology. 1999;199(1):67-9.

29. Shapiro J, Lui H, Tron V, Ho V. Systemic cyclosporine and low-dose prednisone in the treatment of chronic severe alopecia areata: a clinical and immunopathologic evaluation. J Am Acad Dermatol. 1997;36(1):114-7.

30. R Core Team. R: A language and environment for statistical computing. Vienna: R Foundation for Statistical Computing; 2018.

31. Lee JR, Choi SY, Han GS. The combination therapy of cyclosporine and methylprednisolone on severe alopecia areata: 3-year follow-up study. Int J Trichol. 2009;1(1):1.

32. Gadzhigoroeva A. Optimization of severe forms' treatment of alopecia areata using corticosteroids. J Investig Dermatol. 2013;133(5):1392.

33. Gupta AK, Ellis CN, Cooper KD, et al. Oral cyclosporine for the treatment of alopecia areata. A clinical and immunohistochemical analysis. J Am Acad Dermatol. 1990;22(2 I):242-50.

34. Olsen EA, Hordinsky MK, Price VH, et al. Alopecia areata investigational assessment guidelines-Part II. J Am Acad Dermatol. 2004;51(3):448-51.

35. Lai V, Chen G, Gin D, Sinclair R. Cyclosporin for moderate to severe alopecia areata: a double-blind, randomised, placebo-controlled clinical trial of efficacy and safety. Australas J Dermatol. 2019;60: 56.

36. Teshima H, Urabe A, Irie M, Nakagawa T, Nakayama J, Hori Y. Alopecia universalis treated with oral cyclosporine A and prednisolone: immunologic studies. Int J Dermatol. 1992;31(7):513-6. 
37. Lam S, Partovi N, Ting LS, Ensom MH. Corticosteroid interactions with cyclosporine, tacrolimus, mycophenolate, and sirolimus: fact or fiction? Ann Pharmacother. 2008;42(7):1037-47.

38. Açıgöz G, Caliskan E, Tunca M, Yeniay Y, Akar A. The effect of oral cyclosporine in the treatment of severe alopecia areata. Cutan Ocul Toxicol. 2014;33(3):247-52.

39. Constantopoulos A, Tsoumacas C, Tsivitanidou T. Cyclosporine in severe alopecia areata in children. J Eur Acad Dermatol Venereol. 1996;7(2):190-2. 